Microbiological quality of ready-to-eat fresh vegetables and their link to food safety environment and handling practices in restaurants

Faour-Klingbeil, D

http://hdl.handle.net/10026.1/5125

10.1016/j.Iwt.2016.07.051

LWT - Food Science and Technology

Elsevier Ltd.

All content in PEARL is protected by copyright law. Author manuscripts are made available in accordance with publisher policies. Please cite only the published version using the details provided on the item record or document. In the absence of an open licence (e.g. Creative Commons), permissions for further reuse of content should be sought from the publisher or author. 
This is an accepted manuscript of an article published by Elsevier Ltd. in

LWT- Food Science and Technology, 25/07/2016 available at: DOI: 10.1016/j.Iwt.2016.07.051

\section{Accepted Manuscript}

Microbiological quality of ready-to-eat fresh vegetables and their link to food safety environment and handling practices in restaurants

Dima Faour-Klingbeil, Ewen C.D. Todd, Victor Kuri

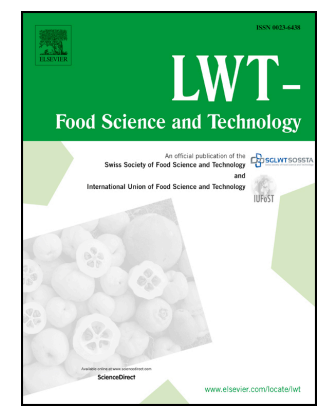

PII:

S0023-6438(16)30462-5

DOI:

10.1016/j.Iwt.2016.07.051

Reference: $\quad$ YFSTL 5625

To appear in: $\quad$ LWT - Food Science and Technology

Received Date: 4 May 2016

Revised Date: 18 July 2016

Accepted Date: 21 July 2016

Please cite this article as: Faour-Klingbeil, D., Todd, E.C.D., Kuri, V., Microbiological quality of readyto-eat fresh vegetables and their link to food safety environment and handling practices in restaurants, LWT - Food Science and Technology (2016), doi: 10.1016/j.Iwt.2016.07.051.

This is a PDF file of an unedited manuscript that has been accepted for publication. As a service to our customers we are providing this early version of the manuscript. The manuscript will undergo copyediting, typesetting, and review of the resulting proof before it is published in its final form. Please note that during the production process errors may be discovered which could affect the content, and all legal disclaimers that apply to the journal pertain.

(C) 2016. This manuscript version is made available under the CC-BY-NC-ND 4.0 license http://creativecommons.org/licenses/by-nc-nd/4.0/

Contact at University of Plymouth:

v.kuri@plymouth.ac.uk 


\title{
Microbiological quality of ready-to-eat fresh vegetables and their link to food safety environment and handling practices in restaurants
}

\author{
Dima Faour-Klingbeil ${ }^{a^{*}}$, Ewen C. D. Todd ${ }^{\mathrm{b},}$ Victor Kuri $^{\mathrm{a}}$ \\ ${ }^{\text {a }}$ School of Biological Sciences, Plymouth University, UK \\ ${ }^{\mathrm{b}}$ Visiting Professor, Department of Nutrition and Food Science, American University of \\ Beirut, Lebanon, and Ewen Todd Consulting, Okemos, Michigan, USA
}

*Correspondence author: dima.faour@gmail.com

\begin{abstract}
1 The increased consumption of ready-to-eat salads outside homes as a result of a fast

2 paced lifestyle, awareness on their nutritional attributes and enhanced processing

3 technology is well documented. This study aimed to determine the microbiological

4 quality of fresh-cut salads vegetables in small and medium sized foodservice

5 establishments (SMEs) and to identify risk factors and handling practices through

6 observational assessment in order to investigate if an association between

7 microbiological quality and visual assessment (inspection) scores can be established.

8 A total of 118 samples fresh-cut vegetable salads were collected from 50 inspected

9 locations and analysed microbiologically, in addition to 49 swabs of knives and cutting

10 boards. There was no statistically significant correlation between visual assessment

11 scores and bacteriological counts on vegetables or cutting boards. Nonetheless, the

12 consistent relationship between inspection ratings on cross-contamination and cleaning

13 components and Listeria spp. levels was statistically significant. This study

14 demonstrated that overall visual assessment scores would not directly reflect the safety

15 of salad vegetables and that the significance of microbiological assessment should be

16 considered in relation to individual inspection components. It is necessary to place
\end{abstract}


effective control measures on cleaning standards and risk of cross-contamination to improve the microbiological safety of fresh salad vegetables in SMEs.

\section{INTRODUCTION}

Fresh vegetables are rich sources of water-soluble vitamins and other nutrients essentials to improve the nutritional status and decrease the risk of cardiovascular disease (Su \& Arab, 2006). However, when they are not carefully prepared, they can be subjected to pathogenic contamination and become hazardous to health particularly when eaten raw (WHO, 2008).

Outbreak investigations often indicate that food service establishments (FSE) greatly contribute to foodborne illnesses involving fresh produce (Jones \& Angulo, 2006; Sodha et al., 2011). Multiple studies revealed that food workers were frequently engaged in unsafe food handling (Clayton \& Griffith, 2004; Manning, 1994; Rajagopal \& Strohbehn, 2013; Sneed, Strohbehn, \& Gilmore, 2004) and that microbial contamination of ready-to-eat (RTE) foods typically occurred in FSEs with food handlers as asymptomatic carriers of pathogenic microorganisms or with poor personal hygiene being involved (McEvoy et al., 2004; Todd et al., 2008). Equipment or surfaces that have not been effectively cleaned or remained wet between cleaning and use also serve as direct routes for contamination of ready to eat foods (Evans et al., 2004; Gill et al., 2001), besides inappropriate storage temperatures, and insufficient cooking (Jones et al., 2008; WHO, 2007).

Less information is available on the relative health risks attributed to handling practices and preparation procedures of raw salad vegetables in SMEs, while other RTE foods and meats have attracted more attention. Inspection tools are essential for capturing information on the general hygiene standards and food handlers' practices Although private or local authorities 'inspections are an 
effective mechanism to assure compliance to food safety standards, there is no a clear indication of a correlation between risk of foodborne illnesses and inspection scores.

There have been many cases when restaurants scored high on inspections and were still having critical violation in food safety(Jones et al., 2004). The significance of association of microbiological quality of RTE vegetables to hygiene inspection scores has not been fully investigated and not sufficiently addressed by researchers. Earlier attempts to establish direct relationship between the results on microbiological analysis of food and visual inspections have not been successful and were mostly based on foods of animal origins(Powell \& Attwell, 1995; Tebbutt \& Southwell, 1989; Wyatt \& Guy, 1980).

This study aimed at conducting observational assessment of the fresh produce handling processes from the receiving stage until display and service to identify risk factors that may be associated with the microbial safety of fresh produce in SMEs which will provide further insights to devise effective preventive measures.

\section{MATERIAL AND METHODS}

\subsection{Observational survey}

A convenience sample of fifty SMEs located in Beirut were observationally assessed for hygiene standards and handling practices of food handlers during the salad vegetable preparation. The survey checklist comprised 6 constructs of 2-7 components for analysis in which the good hygienic practices (GHP) and other prerequisites proposed by the Codex Alimentarius (CAC/RCP 1, 1969) were considered for the visual assessment (Table 1). Additional components in relation to salad preparation practices were also included. The criteria for each component were defined to specify limits for classification. (Supplementary materials). 
68 A reliability analysis test was performed to measure the internal consistency in the

69

70 survey questionnaire. Cronbach's Alpha was 0.928 which indicates a high level of internal consistency for our scale.

\subsection{Additional information}

Additional 8 questions on handling practices of fresh vegetables during receiving, washing and storage were posed to food handlers $(n=80)$ via face-to-face interviews that were conducted in our earlier study on food safety knowledge, attitudes and practices (Faour-Klingbeil et al., 2015). The questions were ranked on a five points rating scale (never $=1$, rarely $=2$, sometime $=3$, often $=4$ and always $=5$ ).

To ensure consistency and unbiased data records, the data collection and visual assessment were carried out by one of the authors (Dima Faour-Klingbeil).

\subsection{Collection of RTE fresh-cut salads vegetables samples}

\subsubsection{Management of samples}

A total of 118 samples of various fresh cut RTE salad vegetables (lettuce, parsley, arugula, coriander, cucumber, tomato and radish) prepared in 50 restaurants were collected after washing and cutting/chopping. On average, 3 types of vegetables were sampled from each restaurant, being subjected to availability and preparation plans at times of visits. They were placed in a sterile bag by food handlers at the end of the preparation process by means of utensils or tools typically used when bringing them into display or storage containers, taking care that they would not touch the inside of the bags.

\subsubsection{Swabs of cutting boards and knoves}

Before cutting/chopping vegetables, surfaces of cleaned cutting boards and knives (normally cleaned by assigned cleaners in well-established restaurants, or food workers 
93 in less developed restaurants) were swabbed by moistened cotton-tip in buffered 94 peptone water (BPW) (Bio-rad laboratories Ltd, Hemel Hempstead, UK) in three

\subsubsection{Microbiological analysis of samples}

Samples of salad vegetables were analysed for the presence of pathogens and hygiene indicators organisms commonly isolated from RTE fresh vegetables, i.e., S. aureus, Salmonella spp., Listeria spp., L. monocytogenes, in addition to total viable counts (APC), E. coli and TCs(Nguz et al., 2005; Sagoo et al., 2001). For microbiological analysis, all the media used were obtained from Bio-Rad Laboratories Ltd., Hemel Hempstead, UK unless otherwise mentioned and samples were analysed according to ISO 16140. Briefly, $10 \mathrm{~g}$ of the samples was weighed into sterile stomacher bags and homogenized with $90 \mathrm{ml}$ sterile peptone buffered water (BPW) for 2 min at medium speed. Aliquots of $0.1 \mathrm{ml}$ of appropriate dilutions were spread in duplicates on suitable media. APC were enumerated on plate-count agar, as for E. coli and TC, $1 \mathrm{ml}$ was dispensed into petri dishes for enumeration by pouring technique using RAPID' E. coli 2 agar. The plates were incubated at $37^{\circ} \mathrm{C}$ for $48 \mathrm{~h}$. Coagulase-positive Staphylococci were enumerated on RAPID'Staph Agar supplemented with egg yolk. For the detection of $S$. aureus, typical presumptive colonies with clear halo resulting from proteolysis of egg yolk were further tested using a latex agglutination test (Pastorex Staph Plus). For the isolation of Salmonella spp., selective enrichment was performed in RappaportVassiliadis-soya broth to be incubated at $41.5^{\circ} \mathrm{C}$. After $24 \mathrm{~h}$ of incubation, a $0.1 \mathrm{ml}$ sample was plated on RAPID'Salmonella agar and plates were incubated at $37^{\circ} \mathrm{C}$ for 
$24 \mathrm{~h}( \pm 2 \mathrm{~h})$. While for L. monocytogenes, Fraser $1 / 2$ broth was used in the selective enrichment and after incubation for $1 \mathrm{~h}$ at $20^{\circ} \mathrm{C}, 0.1 \mathrm{ml}$ of the homogenate was

122 afterwards selectively identified and by Listeria strips (bioMérieux, Marcy l'Etoile,

123 France). Salmonella spp. colonies were identified biochemically by the lysine iron agar and tryptic sugar iron agar slants biotyping technique. Additional confirmation for positive Salmonella spp. colonies and for E. coli was done by the API 20E bacterial identification test strip.

127 The counts were reported as means of colony-forming units (CFU) per $\mathrm{g}$ and were 128 converted into $\mathrm{Log} \mathrm{CFU} / \mathrm{g}$.

129 Additionally, for statistical purposes, Listeria spp were ranked into 3 levels (Above 100 CFU/g, Below $100 \mathrm{CFU/g}$, and Not detected).

\subsubsection{Swab tests}

132 The swabs in $5 \mathrm{ml}$ tube of BPW were vortexed vigorously for $1 \mathrm{~min}$. Tenfold serial 133 dilutions were spread-plated onto duplicate plates of PCA, RAPID'Staph agar supplemented with egg yolk and RAPID'E. coli 2 agar.(Sneed, Strohbehn, Gilmore, et al., 2004). Counts were expressed as log CFU/swabbed area.

\section{DATA HANDLING AND STATISTICAL ANALYSIS}

138 All data were analysed using the IBM SPSS Statistics (SPSS) version 22.

139 Observational assessment of each of the 26 components was rated on three units scale 140 (adequate $=3$, incomplete $=2$, inadequate $=1$ ). The sum of the total awarded units on adequacy level (visual assessment scores) was converted to 100 points. 
142 Frequency of levels in compliance (adequacy level) for each visually inspected 143 component was obtained. Bacterial levels differences among different compliance levels 144 were compared using One-way ANOVA, and independent t-test was performed to 145 compare results between two groups.

146 The association between bacterial counts and overall visual assessment scores was 147 assessed by Pearson correlation and multiple linear regression analysis; binomial 148 regression was performed for S. aureus.

149 The percentage variances in bacterial counts (Log CFU/g) explained by individual 150 inspection components were determined by correlation ratio $\operatorname{ETA}^{2}$ ( $\eta^{2}$ ratio). In the case 151 Listeria and S. aureus, Spearman's rho and cross-tabulations Somer'd tests were also applied.

\section{RESULTS}

\subsection{Overall results on food handlers 'practices and hygiene conditions on premises}

Results of the visual inspections of FSEs and food handlers' practices during the preparation of fresh salads vegetables indicated structural inadequacies and insufficient fulfilment of hygiene prerequisites with a mean score on overall adequacy level of 55.5 \pm 19.0 over 100 possible points (Figure 1), with the majority of locations being below scores of 50-70. Over half (54\%) of the food premises failed to fulfil the basic hygienic requirements for clean floors, equipment and food contact surfaces, while a third had limitations in the structural conditions (Figure 2). Recorded incompliances included open drains, gaps and holes on windows and walls and evidence of pests (cockroaches) at the time of the survey. Furthermore, $22 \%$ had not a completely well maintained premise. More than a half $(52 \%)$ of the FSEs had space limitations compromising the 
separate areas for the preparation of raw meats and RTE foods. It was notable that the inappropriate sanitation measures were not applied in $60 \%$ of the premises (Figure 2).

Only $8 \%$ of FSEs had cleaning schedules, and showed evidence of temperature monitoring records of salads display and cold storage.

171 In addition, a large percentage of food businesses (64\%) lacked hand washing sinks; or designated sinks for washing fresh fruits and vegetables were either absent (32\%) or if fitted, it was not clean and used for others purposes such as washing hands or implements used with raw meat and cooked foods (40\%). More concerning, gloves were used correctly and appropriately during the salad preparation in just a fifth (20\%) of the premises.

Risks of cross-contamination were detected in $48 \%$ of the premises, for example by the presence of heavily chipped or unclean cutting boards, unfamiliarity of food handlers with the concept of color-coding or separate use of utensils and cutting boards for raw meat and fresh vegetables. There was misuse of colour-coded cutting boards in $18 \%$ of FSE's where colour-coded cutting boards were used for several types of food. The component "frozen foods are thawed properly" was not observed in $74 \%$ of the premises visited, yet it was inadequately performed in $14 \%$ of the locations where frozen fish or chicken soaked in water were noted at the time of the visit.

\subsection{Handling practices and the process of salads vegetables preparation}

Fresh vegetables were received during the mornings (7-9 a.m.) in plastic crates transported produce in uncooled vehicles (Table 2). In some cases, the person in charge or business owner purchased the daily needs from the central market or nearby groceries. More than two thirds of the respondents reported sourcing the fresh produce from the same 
191

192

193

194

195

supplier (68.4\%), and washing the vegetables before cutting (77\%). In general, preparation started early, particularly with bundles of parsley which were finely chopped for serving later in the day in traditional salads and appetizers. Parsley leaves were chopped before washing in $34 \%$ of FSEs, which is consistent with the typical preparation sequence at homes (Figure 3), aiming to keep the texture of the leaves longer, as they would becoming soggy if they are washed ahead of time. About a third of the food businesses did not sanitize fresh vegetables, and used only water to wash them. However, a large proportion (84\%) reported that the wash water was neither treated nor filtered. With long-standing shortages of potable water in Lebanon, restaurants, and homes, purchase water, often of uncertain quality and source, which is then stored in tanks. Out of the $56 \%$ using sanitizers, $21 \%$ used sodium dichloroisocyanurate (NaDCC) and more than a third (45\%) applied a post-sanitization water rinse to remove the remaining taste or odour, respectively. It was noted during inspection discussions and observations that automated systems regulating the concentrations of chemical sanitizers in addition to water filters were in place, in some corporate-managed restaurants. On other places (24\%), incorrect dilutions of sanitiser was observed, typically as haphazard mixing of vinegar or NaDCC tablets in water. The majority reported that fresh produce was kept in cold storage, whereas this was actually only observed in $38 \%$ of the premises, with inadequate alternatives including stairways, kitchen floors of spaces in crowded production areas.

\subsection{The microbiological quality of fresh salads vegetables}

Results on microbiological analysis of fresh-cut salad vegetables are presented in (Table 3 and 4).

The mean APC levels ranged from 2.90 to $7.38 \mathrm{Log}$ CFU/g, with counts above $10^{7} \mathrm{CFU} / \mathrm{g}$ recorded for $17 \%$ of the samples. The prevalence rate was substantially high 
in TCs $(79.6 \%, 94 / 118)$. TCs were found between $1.72-6.40 \mathrm{Log}$ CFU/g, of which

$21738 \%$ were $>4$ Log CFU/g. Whereas, E.coli was isolated from 31.3\% (37/118), with

218 bacterial loads ranging from less than 1.00 to $7.15 \mathrm{Log} C F U / g$, and the incidence rate

219 was $64.8 \%$ of the positive samples (24/37) for counts higher than $100 \mathrm{CFU} / \mathrm{g}$.

220 More than two thirds $(41.5 \%)$ of the samples were found to contain S. aureus. In addition, Listeria spp. were isolated from $70.6 \%$ of the samples. The overall incidence level was $53 \%$ for counts above $100 \mathrm{CFU} / \mathrm{g}$, with an average of $3.24 \mathrm{Log} \mathrm{CFU} / \mathrm{g}$. $\mathrm{L}$. monocytogenes had a prevalence rate of $3.7 \%$ mainly in arugula, parsley and lettuce, whereas Salmonella was detected in $0.9 \%$, (lettuce).

Results on recovered microorganisms from contact surfaces (cutting boards and knives) are presented in Table 5. The microbial levels varied from below detection limits (10 CFU/swabbed area) to generally high levels. E.coli was isolated from $30.6 \%$ (15/49) of contact surfaces (knives and cutting boards); of those, the mean values were found between $2.70-7.02 \mathrm{Log}$ CFU/swabbed area, whereas the incidence rate in TCs was higher $(53.0 \%, 26 / 49)$ with levels between 4.88 - 8.40 Log CFU/swabbed area. There was no statistically significant correlation between the microbial counts recovered from contact surfaces and the ratings on the adequacy level of sanitation of work surfaces $(\mathrm{p}>0.05)$.

Overall, the analysis of data shows no statistical significant differences and inconsistent trends in bacterial counts of different visual assessment rankings for each individual inspection component $(\mathrm{p}>0.05)$. For instance, higher counts of TCs were observed on lettuce and parsley obtained from premises with inadequate sanitary conditions and unsafe handling practices, however this was not the case with cucumbers (Table 6). Also, the frequency in the distribution of bacterial levels on lettuce and parsley in relation to hygiene scores shows that high concentration levels were grouped at lower 
scores (Figure 4). Likewise, the mean levels of coagulase-positive Staphylococcus spp. were higher on all vegetables prepared on premises lacking handwashing sinks (Figure $5)$.

244 There was no correlation between total visual assessment scores and bacterial levels

245 ( $\mathrm{p}>0.05)$. However, independent $\mathrm{t}$-test still reveals a significant difference $(\mathrm{t}=-2.198,81$, $\mathrm{p}=0.03$ ), between inspection scores for premises with Listeria counts above $100 \mathrm{CFU} / \mathrm{g}$

247 (53.44 \pm 18.39$)$ and those where the organism was not detected $(64.48 \pm 26.12)$. When Eta correlation and non-parametric tests were further performed for this organism, no significant correlations of microbial results with all individual inspection component $(p>0.05)$ were shown, while correlation tests and cross tabulations somer'd test revealed a significantly low and moderate association of Listeria levels with the inspection components related to cross contamination, handling practices, zoning and availability of handwashing sinks $(\mathrm{p}<0.05)$ (Figure 6). This association level was consistent with linear regression establishing that Listeria spp levels may be predicted by the visual assessment scores $(F 1,103)=11,614, p=0.001$, but the score accounted for only $10.5 \%\left(\mathrm{R}^{2}\right)$ of the explained variability in Listeria levels in vegetables. Given the small value of $\mathrm{R}^{2}$, the prediction model using the visual assessment scores is not accurate. However and more interestingly, as we considered each inspected component individually, $\mathrm{Eta}^{2}$ coefficients showed higher percentage in variations in Listeria spp. counts (30-34\%) which were explained and attributed to cross contamination and cleaning operations components $(\mathrm{p}<0.05)$.

\section{DISCUSSION}

\subsection{Food safety practices and microbial quality of fresh salads vegetables}


264 A number of food safety practices concerns were identified in this study. The general

265 lack of cleaning and sanitization procedures combined with a clear evidence of cross-

266 contamination opportunities were generally reflected in the overall unsatisfactory

267 quality of RTE vegetables. The majority of SMEs seemed to be unaware of the

268 significance of applying control measures when handling vegetables and of the

269 fundamental requirements for separate handwashing and vegetables washing sinks. APC

270 were above the specified limits for RTEs, 7 Log CFU/g, in $17 \%$ of the analysed

271 samples. when APC count is $>10^{6} \mathrm{CFU} / \mathrm{g}$, it may not necessarily relate to food safety

272 hazards; in many of these cases, there is a predominant microorganism from an

273 environmental source (PHLS, 2000) such as the processing stages involving handling,

274 cutting, slicing and improper storage as well as display conditions (Abadias et al.,

275 2012); Nguz et al. (2005) showed that chlorine treated fresh-cut organic mixed

276 vegetables were still found to harbour high levels of TCs (5.9 Log CFU/g) and it was

277 proposed that high loads of coliforms in RTE vegetables at retails levels is directly

278 influenced by intense use of untreated manure during pre-harvest, and extensive

279 handling during postharvest (Aycicek et al., 2006). In our earlier study, TCs $\geq 5 \log$

280 CFU/g were isolated from more than two third of the fresh vegetables (69\%) coming

281 from locations with alarming deficits at harvest and post-harvest washing, storage and

282 distribution stages (Faour-Klingbeil et al., 2016).

283 According to the EC legal food safety criteria and the UK Public Health Laboratory

284 Service (PHLS) microbiological guidelines for RTE foods sampled at the point of sale,

285 for category 5 fresh vegetables (HPA, 2009; PHLS, 2000), our study results on

286 microbial contamination levels of more than half of the RTE salad vegetables were

287 unsatisfactory due to E. coli and Listeria spp. counts that exceeded the criteria limits 
$>10^{2} \mathrm{CFU} / \mathrm{g}$ indicating poor hygienic practices and sanitary conditions (Gilbert et al., 2000).

Listeria spp. are rarely implicated in illnesses involving produce, however, they may indicate a significant failure of hygiene standards in the preparation and /or storage of

292 fresh vegetables(Gilbert et al., 2000) which in turn are considered hazardous for L.monocytogenes contamination (Ponniah et al., 2010). Presence of L.monocytogenes and Salmonella spp. were traced back to samples obtained from restaurant that had no handwashing sinks, fresh vegetable washing sinks, or adequate preparation and storage areas or surfaces and the corresponding visual assessment score recorded 32 over 100

297 possible points.

The lacking of handwashing sinks explained the fact that proper handwashing before and after use of gloves were not commonly observed, although many other factors could interfere as well. High frequency of $S$. aureus indicates poor hygiene practices of food handlers, the latter being known to be carriers of this pathogen (Todd et al., 2008) and may contribute in direct contamination of RTE fresh vegetables and contact surfaces via the hands (Todd et al., 2008).

\subsection{Food contact surfaces}

The PHLS recommended guidelines for cleaned contact surfaces specified levels of total viable microorganisms less than $80 \mathrm{CFU} / \mathrm{cm}^{2}$ as satisfactory, $80-10^{3} \mathrm{CFU} / \mathrm{cm}^{2}$ is borderline, and over $10^{3} \mathrm{CFU} / \mathrm{cm}^{2}$ is unsatisfactory been associated with poor hygiene practices (Herbert et al., 1990). PCA counts $\geq 10^{3} \mathrm{CFU} / \mathrm{cm}^{2}$ was recorded for $33 / 49$ swabbed surface. The overall incidence rate of E.coli was $15 / 49$ with counts $\geq 1$

$310 \mathrm{CFU} / \mathrm{cm}^{2}$, whereas E. coli counts $\geq 10^{3} \mathrm{CFU} / \mathrm{cm}^{2}$ were recorded for $10 / 49$ of swabs. TCs 311 and Staphylococcus spp. were found in 26/49 and 39/49 of swabs with counts $312 \geq 10^{3} \mathrm{CFU} / \mathrm{cm}^{2}$. In this regard, the high microbial population size on contact surfaces 
313 offered an additional assumption for the actual contamination observed on the washed

314 salad items, particularly that sanitization and cleaning operations were lacking in a great

315 majority of locations. Sneed, Strohbehn, Gilmore, et al. (2004) indicated that inadequate

316 sanitation and recontamination problems were actually related to high aerobic plate

317 counts recovered from cutting boards. Non-sanitized and scratched cutting surfaces,

318 combined in some cases with misuse of sanitizers dilution, are an appropriate

319 environment for harbouring pathogens that have the propensity to form biofilm on

320 surfaces (Pui et al., 2011) and resist washing processes (Ravishankar et al., 2010).

321 As RTE fresh vegetables were obtained after washing, the existing microbiological

322 characteristics do raise further doubts as to the implication of water quality. It is well recognized that natural resources and water supply in Lebanon endures a high risk of chemical and microbial pollution (Houri \& El Jeblawi, 2007; Jurdi, 1992), at the same time, it is substantiated that washing with water of unsatisfactory microbial quality can serve as a vehicle for dispersion of microorganisms (Holvoet et al., 2013) and was the primary cause for the homogenous spread of Salmonella Enteritidis to fresh-cut vegetables during processing (Perez-Rodriguez et al., 2014). The quality of water used for washing or in post-sanitization rinsing process in SMEs should be addressed in future studies as a critical element to maintain fresh vegetables safety specially when more restaurants nowadays rely on purchasing water of unknown sources, usually coming in tankers collected from spring water but may or may not be chlorinated, to compensate for the shortage in water supply..

5.3 Association of microbial counts to visual assessment scores and inspection components

Our data revealed an inconsistent association between the bacterial counts and visual assessment scores of handling practices and hygiene conditions. As we also studied the 
possibility of association to each single inspection component, the microbiological quality of salad vegetables did not show any direct correlation with each individual inspected component. It was found that the cell counts were either corresponding or conflicting in trend across ranking on adequacy level and types of produce. The complexity of the interfering factors during sampling of RTE fresh vegetables from different operational conditions (e.g., environment and storage temperature, receiving and pre-receiving conditions of fresh vegetables, preparation stages of fresh cut vegetables, sampling methods) challenges the possibility to detect a clear cut trend and association. Add to this, large number of samples might be needed to investigate such a trend. Our findings are in accordance with a study by Powell and Attwell (1995) where a link between the total viable counts and S.aureus on turkey and ham and the compliance rate to different inspection components was not established. Findings of earlier studies did not as well confirm such an association with the microbiological quality of foods of meat origin (Tebbutt \& Southwell, 1989; Wyatt \& Guy, 1980). Kuri et al. (1996) found that microbial indicators in meats, including pathogen prevalence, were not correlated to total hygiene scores of meat retailers, nor to temperature of samples, but they were related to type of retailer or origin of product.

We actually noted higher population size of hygiene indicators on some samples prepared under inadequate hygiene conditions, although a statistically significant correlation with the inspection scores failed. According to our results, it may be reasonable to consider that low visual assessment scores on the hygiene standards and handling practices probably indicate unsatisfactory microbial quality and likelihood for risks of salad vegetables contamination with L.monocytogenes, however, this association was only significant in relation to individual components related to crosscontamination and effective cleaning. The total visual assessment score can be affected 
363

364

365

366

367

368

369

370

371

372

373

374

376

377

378

379

380

381

382

383

384

by a number of possible combinations of ranking levels of the 26 variables; a low inspection score might not necessarily indicate low ratings of all the critical components that have direct impact on the microbiological quality of vegetables. Hence, inspections should focus upon factors most likely to be responsible for foodborne infection or high microbial levels associated with RTE vegetables.

\section{CONCLUSION}

Links between the visual assessment scores on the overall food safety performance and the microbiological quality of RTE fresh vegetables are not simple to establish and were not clearly correlated. The total visual assessment scores per se would not directly indicate the microbiological safety of RTE vegetables in restaurants. However, variations in microbial counts and a significant correlation of high Listeria levels with the inadequate cleaning performances and cross-contamination preventive measures were recorded, which imply that shortfalls in those particular practices may possibly indicate pathogenic contamination of fresh vegetables.

Also, this study found high microbial loads in RTE vegetables that could serve as an indicator for the need to promote awareness on the critical areas commonly identified in SMEs and as guidance for local authorities to target those that may mostly affect the safety of fresh vegetables. It underscored the considerable requisite for improvement in sanitary and good hygienic practices and for vigilant cleaning and sanitation procedures to reduce or eliminate contamination and cross-contamination risks that may occur at pre-farm gate and throughout the supply chain stages. Therefore, applications of critical control points for the preparation of fresh salad vegetables and personnel training on the hazards associated with their preparation are fundamentals to improve the food safety of fresh produce particularly when prepared in small working facilities in SMEs. 


\section{ACKNOWLEDGEMENTS}

389 The authors gratefully acknowledge the support provided by the Department of

390 Nutrition and Food Science, American University of Beirut for partially funding this

391 research work through a grant from the Lebanese National Council for Scientific 392 Research (CNRS) \#102598.

393 


\section{REFERENCES}

Abadias, M., Alegre, I., Oliveira, M., Altisent, R., \& Viñas, I. (2012). Growth potential of Escherichia coli $\mathrm{O} 157: \mathrm{H} 7$ on fresh-cut fruits (melon and pineapple) and vegetables (carrot and escarole) stored under different conditions. Food Control, 27(1), 37-44. doi: http://dx.doi.org/10.1016/j.foodcont.2012.02.032

Aycicek, H., Oguz, U., \& Karci, K. (2006). Determination of total aerobic and indicator bacteria on some raw eaten vegetables from wholesalers in Ankara, Turkey. International Journal of Hygiene and Environmental Health, 209(2), 197-201. doi: 10.1016/j.ijheh.2005.07.006

CAC/RCP 1(1969). Recommended international code of practice general principles of food hygiene (Revision 4 - 2003). Retrieved from:

http://www.mhlw.go.jp/english/topics/importedfoods/guideline/dl/04.pdf

Clayton , D., \& Griffith, C. (2004). Observation of food safety practices in catering using notational analysis. British Food Journal, 106, 211-227.

Evans, J. A., Russell, S. L., James C., \& Corry, J. E. L. (2004). Microbial contamination of food refrigeration equipment Journal of Food Engineering, 62, 225-232.

Faour-Klingbeil, D., Kuri, V., \& Todd, E. (2015). Investigating a link of two different types of food business management to the food safety knowledge, attitudes and practices of food handlers in Beirut, Lebanon. Food Control, 55, 166-175.

Faour-Klingbeil, D., Murtada, M., Kuri, V., \& Todd, E. (2016). Understanding the routes of contamination of ready-to-eat vegetables in the Middle East. Food Control, 62, 125-133. doi: http://dx.doi.org/10.1016/j.foodcont.2015.10.024

Gilbert, R., de Louvois, J., Donovan, T., Little, C., Nye, K., Ribeiro, C., Bolton, F. (2000). Guidelines for the microbiological quality of some ready-to-eat foods sampled at the point of sale. PHLS Advisory Committee for Food and Dairy Products. Communicable Disease and Public Health, 3(3), 163-167.

Gill, C. O., Bryant, J., \& Badoni, M. (2001). Effects of hot water pasteurizing treatments on the microbiological condition of manufacturing beef used for hamburger patty manufacture. International Journal of Food Microbiology, 63(3), 243-256.

Herbert, M., Donovan, T., \& Manger, P. (1990). A study of the microbial contamination of working surfaces in a variety of food premises using the traditional swabbing technique and commercial contact slides . In Ashford (Ed.).

Holvoet, K., Sampers, I., Callens, B., Dewulf, J., \& Uyttendaelea, M. (2013). Moderate Prevalence of Antimicrobial Resistance in Escherichia coli Isolates from Lettuce, Irrigation Water, and Soil. Applied and Environmental Microbiology 79(21), 6677-6683.

Houri, A., \& El Jeblawi, S. W. (2007). Water quality assessment of Lebanese coastal rivers during dry season and pollution load into the Mediterranean Sea. Journal of Water and Health, 5(4).

HPA. (2009). Guidelines for Assessing the microbiological safety of ready-to-eat foods. Health Protection Agency. .

Jones, S. L., Parry, S. M., O'Brien, S. J., \& Palmer, S. R. (2008). Are staff management practices and inspection risk ratings associated with foodborne disease outbreaks in the catering industry in England and Wales? Journal of Food Protection, 71(3), 550-557.

Jones , T. F., \& Angulo, F. J. (2006). Eating in restaurants: a risk factor for foodborne disease? Clin Infect Dis, 43(10), 1324-1328. doi: 10.1086/508540 
Jones, T. F., Pavlin, B., LaFleur, B., Ingram, L., \& Schaffner, W. (2004). Restaurant inspection Scores and foodborne disease. Emerging Infectious Diseases 10(4), 688-692.

Jurdi, M. (1992). A national study on the quality of potable water in Lebanon. Proceedings of the national workshop of the status of water in Lebanon, United Nations International Children's Emergency Fund (UNICEF). Beirut, Lebanon pp. 145-173 (in Arabic).

Kuri, V., Madden, R. H., \& Collins, M. A. (1996). Hygienic quality of raw pork and chorizo (raw pork sausage) on retail sale in Mexico City. Journal of Food Protection 59 (2), 141-145.

Manning, C. K. (1994). Food safety knowledge and attitudes of workers from institutional and temporary foodservice operations. Journal of the American Dietetic Association, 94(8), 895-897. doi: http://dx.doi.org/10.1016/0002$\underline{\text { 8223(94)92372-8 }}$

McEvoy, J. M., Sheridan, J. J., Blair, I. S., \& McDowell, D. A. (2004). Microbiological contamination of beef carcasses in relation to hygiene assessment based on criteria used in EU Decision 2001/47/EC. International Journal of Food Microbiology, 92, 217-225.

Nguz, K., Shindano, J., Samapundo, S., \& Huyghebaert, A. (2005). Microbiological evaluation of fresh-cut organic vegetables produced in Zambia. Food Control, 16(7), 623-628. doi: http://dx.doi.org/10.1016/j.foodcont.2004.07.001

Perez-Rodriguez, F., Saiz-Abajo, M. J., Garcia-Gimeno, R. M., Moreno, A., Gonzalez, D., \& Vitas, A. I. (2014). Quantitative assessment of the Salmonella distribution on fresh-cut leafy vegetables due to cross-contamination occurred in an industrial process simulated at laboratory scale. International Journal of Food Microbiology, 184, 86-91. doi: 10.1016/j.ijfoodmicro.2014.05.013

PHLS. (2000). Microbiological guidelines for some ready-to-eat foods sampled at the point of sale. . Communicable Disease and Public Health, 3, 163-167.

Ponniah, J., Robin, T., Paie, M., Radu, S., Ghazali, F., Kqueen, C., Malakar, P. (2010). Listeria monocytogenes in raw salad vegetables sold at retail level in Malaysia. Food Control, 21, 774-778.

Powell, C., \& Attwell, R. W. (1995). A comparative study of food retail premises by means of visual inspection and microbiological quality of food. Epidemiology and Infection, 114, 143-151.

Pui , C. F., Wong, W. C., Chai, L. C., Lee, H. Y., Tang, J. Y. H., Noorlis, A., Son, R. (2011). Biofilm formation by Salmonella Typhi and Salmonella Typhimurium on plastic cutting board and its transfer to dragon fruit. International Food Research Journal, 18, 31-38.

Rajagopal, L., \& Strohbehn, C. H. (2013). Observational assessment of glove use behaviors among foodservice workers in a university dining setting: Testing a visual intervention tool. Food Protection Trends, 33(5), 315-324.

Ravishankar, S., Zhu, L., \& Jaroni, D. (2010). Assessing the cross contamination and transfer rates of Salmonella enterica from chicken to lettuce under different food-handling scenarios. Food Microbiology, 27(6), 791-794. doi: http://dx.doi.org/10.1016/j.fm.2010.04.011

Sagoo, S. K., Little, C. L., \& Mitchell, R. T. (2001). The microbiological examination of ready-to-eat organic vegetables from retail establishments in the United Kingdom. Letters in Applied Microbiology, 33(6), 434-439. 
Sneed, J., Strohbehn, C., \& Gilmore, S. (2004). Food safety practices and readiness to implement HACCP programs in assisted-living facilities in Iowa. Journal of American Dietetic Association 104(11), 1678-1683.

Sneed, J., Strohbehn, C., Gilmore, S., \& Mendonca, A. (2004). Microbiological evaluation of foodservice contact surfaces in Iowa assisted-living facilities. Journal of American Dietetic Associatio., 104(11), 1722-1724.

Sodha, S. V., Lynch, M., Wannemuehler, K., Leeper, M., Malavet, M., Schaffzin, J., Braden, C. (2011). Multistate outbreak of Escherichia coli O157:H7 infections associated with a national fast-food chain, 2006: a study incorporating epidemiological and food source traceback results. Epidemiology and Infection, 139(2), 309-316. doi: 10.1017/S0950268810000920

Su, L. J., \& Arab, L. (2006). Salad and raw vegetable consumption and nutritional status in the adult US population: results from the Third National Health and Nutrition Examination Survey. Journal of American Dietetic Association, 106(9), 13941404. doi: 10.1016/j.jada.2006.06.004

Tebbutt, G., \& Southwell, J. (1989). Comparative study of visual inspections and microbiological sampling in premises manufacturing and selling high-risk foods. Epidemiology and Infection 103, 475-486.

Todd, E. C., Greig, J. D., Bartleson, C. A., \& Michaels, B. S. (2008). Outbreaks where food workers have been implicated in the spread of foodborne disease. Part 5. Sources of contamination and pathogen excretion from infected persons. Journal of Food Protection, 71, 2582-2595.

WHO. (2007). Food safety and foodborne illness. Retrieved from

WHO. (2008). Microbiological hazards in fresh fruits and vegetables. WHO report :Microbiological Risk assessment series.

Wyatt, C., \& Guy, V. (1980). Relationship of microbial quality of retail meat samples and sanitary conditions. Journal of Food Protectection 43, 385-389. 
Table 1. The six different constructs comprised in the visual assessment survey in SMEs

\begin{tabular}{|c|c|}
\hline Inspection constructs & Individual Inspection Components \\
\hline Construct 1: Structural compliance & $\begin{array}{l}\text { - General maintenance conditions and evidence of } \\
\text { pest in the production environment } \\
\text { - Zoning (separation of fresh produce from raw } \\
\text { meat and poultry) } \\
\text { - All major pieces of equipment such fridges, } \\
\text { freezers ovens, hot holding equipment, cold } \\
\text { holding equipment are fitted with working } \\
\text { temperature monitoring gauges } \\
\text { - Availability of proper handwashing sink }\end{array}$ \\
\hline Construct 2: Personal Hygiene & $\begin{array}{l}\text { - Wearing hair cap } \\
\text { - Appropriately clean personnel protective } \\
\text { clothing }\end{array}$ \\
\hline Construct 3: Sanitation & $\begin{array}{l}\text { - Clean floors, walls, overall facilities and } \\
\text { implements } \\
\text { - Waste containers are covered, kept clean } \\
\text { - Sanitisers for work surfaces readily available for } \\
\text { use during food preparation } \\
\text { - Containers used to drain vegetables are kept } \\
\text { clean }\end{array}$ \\
\hline $\begin{array}{l}\text { Construct 4: Evidence of procedures and } \\
\text { management system control }\end{array}$ & $\begin{array}{l}\text { - Records keeping for verification of temperature } \\
\text { monitoring and system audits (during cooking, } \\
\text { cooling, storing) } \\
\text { - Cleaning system and schedule } \\
\text { - Where a chemical sanitiser is used, there are } \\
\text { records to show levels are maintained }\end{array}$ \\
\hline $\begin{array}{l}\text { Construct 5: Contamination and Cross } \\
\text { contamination control measures }\end{array}$ & $\begin{array}{l}\text { - Staff cleaning tools are stored in appropriate } \\
\text { manner and not at risk of contaminating food or } \\
\text { equipment during preparation } \\
\text { - Staff personal belongings are stored in } \\
\text { appropriate manner and not at risk of } \\
\text { contaminating food or equipment during } \\
\text { preparation? } \\
\text { - Received fresh vegetable are stored in protected } \\
\text { - Wash } \\
\text { - Unprocessed raw vegetables are prepared so that } \\
\text { contamination and cross- contamination does } \\
\text { not occur (separate cutting boards and utensils) } \\
\text { - Visitors or unauthorized staff are granted } \\
\text { protective clothing upon entry } \\
\text { Entry for authorized personnel only }\end{array}$ \\
\hline $\begin{array}{l}\text { Construct 6: Safe and hygienic handling } \\
\text { practices }\end{array}$ & $\begin{array}{l}\text { - Appropriate use of gloves and handwashing } \\
\text { - Frozen food is properly thawed } \\
\text { - Vegetable sanitizers are made up correctly } \\
\text { - Food on hold is covered }\end{array}$ \\
\hline
\end{tabular}


Table 2 Frequency of self-reported handling practices of fresh vegetables in foodservice establishments

\begin{tabular}{|c|c|c|c|c|c|}
\hline \multirow[t]{2}{*}{ Process } & \multicolumn{5}{|c|}{$\begin{array}{l}\text { Frequency of handling practices } \\
\qquad \mathrm{N}(\%)\end{array}$} \\
\hline & Always & Often & Sometimes & Rarely & Never \\
\hline $\begin{array}{l}\text { Are fresh vegetables delivered } \\
\text { from one supplier/source? }\end{array}$ & $52(68)$ & $17(22)$ & $5(7)$ & $1(1)$ & $1(1)$ \\
\hline $\begin{array}{l}\text { Are fresh leafy vegetables or/and } \\
\text { pre-cut vegetables delivered } \\
\text { cooled? }\end{array}$ & $2(3)$ & $0(0)$ & $2(3)$ & $0(0)$ & $72(94)$ \\
\hline $\begin{array}{l}\text { Is the washing water used for } \\
\text { fresh vegetables and fruits } \\
\text { chlorinated? }\end{array}$ & 13(17) & $0(0)$ & $0(0)$ & $0(0)$ & $64(83)$ \\
\hline $\begin{array}{l}\text { Do you wash the vegetables } \\
\text { before cutting? }\end{array}$ & $51(77)$ & $1(1)$ & (1) & $0(0)$ & $13(20)$ \\
\hline $\begin{array}{l}\text { If applicable: how often you } \\
\text { record the temperature of the } \\
\text { display salad bar? }\end{array}$ & $12(35)$ & $0(0)$ & & $0(0)$ & $22(65)$ \\
\hline $\begin{array}{l}\text { The received fresh vegetables are } \\
\text { kept in the cold storage } \\
\text { room/fridge }\end{array}$ & 67 (93) & & $1(1)$ & $0(0)$ & $4(6)$ \\
\hline $\begin{array}{l}\text { The washed and cut vegetables } \\
\text { for salads and garnishes are held } \\
\text { at room temperature before } \\
\text { preparation/service }\end{array}$ & $17(26$ & $0(0)$ & $2(3)$ & $0(0)$ & $47(71)$ \\
\hline
\end{tabular}


Table 3. Microbial loads of different fresh salads vegetables

\begin{tabular}{lccc}
\hline Produce & $\mathbf{N}$ & PCA $^{\dagger}$ & Coliforms $^{\dagger}$ \\
\hline Lettuce & 30 & $5.50 \pm 1.55$ & $3.89 \pm 2.19$ \\
Parsley & 34 & $5.42 \pm 1.32$ & $4.48 \pm 2.16$ \\
Cucumber & 18 & $4.60 \pm 2.01$ & $3.52 \pm 2.10$ \\
Radish & 9 & $5.09 \pm 2.20$ & $1.72 \pm 2.68$ \\
Mint & 11 & $3.92 \pm 2.74$ & $3.93 \pm 2.75$ \\
Coriander & 1 & $7.38 \pm 0.00$ & $6.40 \pm 0.00$ \\
Aragula & 5 & $3.99 \pm 2.44$ & $3.30 \pm 3.06$ \\
Tomato & 3 & $2.90 \pm 2.57$ & $2.13 \pm 2.20$ \\
Lettuce & 4 & $5.35 \pm 1.59$ & $3.20 \pm 1.49$ \\
Iceberg & 3 & $4.54 \pm 0.77$ & $1.46 \pm 2.53$ \\
\hline
\end{tabular}

$\dagger$ Values are mean Log CFU/g \pm standard deviation.

The minimum detection limit was $10 \mathrm{CFU} / \mathrm{g}$. 
Table 4.Mean levels of E.coli and coagulase-positive Staphylococcus spp. on salads vegetables

\begin{tabular}{lccc}
\hline Produce & $\mathbf{N}$ & $\begin{array}{c}\boldsymbol{E} \text {. Coli } \\
\text { Log CFU/g } \pm \text { SD }(\text { min-max })\end{array}$ & $\begin{array}{c}\text { Staphylococcus spp. } \\
\text { Log CFU/g } \pm \text { SD }(\min -\mathrm{max})\end{array}$ \\
\hline Lettuce & 30 & $0.92 \pm 1.80(<1.00-7.15)$ & $2.89 \pm 2.28(<1.00-7.76)$ \\
Parsley & 34 & $0.70 \pm 1.50(<1.00-5.40)$ & $2.93 \pm 187(<1.00-6.16)$ \\
Cucumber & 18 & $1.30 \pm 1.43(<1.00-3.40)$ & $2.01 \pm 1.99(<1.00-5.45)$ \\
Radish & 9 & $0.35 \pm 0.88(<1.00-2.65)$ & $2.84 \pm 2.37(<1.00-6.48)$ \\
Mint & 11 & $1.36 \pm 1.78(<1.00-4.91)$ & $2.69 \pm 2.08(<1.00-5.62)$ \\
Coriander & 1 & $1.30 \pm 0.91(<1.00-1.30)$ & 4.04 \\
Aragula & 5 & $0.92 \pm 1.45(<1.00-3.30)$ & $2.76 \pm 1.67(<1.00-4.15)$ \\
Tomato & 3 & $<1.00$ & $2.00 \pm 2.00(<1.00-4.00)$ \\
lettuce & 4 & $<1.00$ & $4.47 \pm 1.73(2.30-6.00)$ \\
Iceberg & 3 & $0.33 \pm 0.58(<1.00-1.00)$ & $1.83 \pm 1.58(<1.00-2.78)$ \\
\hline
\end{tabular}

The minimum detection limit was $10 \mathrm{CFU} / \mathrm{g}$. 
Table 5. Bacterial counts recovered from two contact surfaces

\begin{tabular}{|c|c|c|c|c|c|}
\hline \multirow{2}{*}{$\begin{array}{l}\text { Contact } \\
\text { surface }\end{array}$} & \multirow{2}{*}{$\mathrm{N}$} & \multicolumn{4}{|c|}{ Mean log CFU/swabbed area (min-max) } \\
\hline & & PCA & Staphylococcus spp & E.coli & Total coliforms \\
\hline $\begin{array}{l}\text { Chopping } \\
\text { board } \dagger\end{array}$ & 29 & $4.99(<1.00-8.40)$ & $4.42(<1.00-8.40)$ & $1.19(<1.00-6.02)$ & $2.62(<1.00-8.40)$ \\
\hline Knife* & 20 & $5.62(<1.00-8.40)$ & $4.62(<1.00-7.98)$ & $1.13(<1.00-5.95)$ & $4.31(<1.00-8.40)$ \\
\hline
\end{tabular}

$\dagger$ Cuttinng board swabbed area of $50 \mathrm{~cm}^{2}$

${ }^{*}$ Knife (no defined area - ca.10-20 $\mathrm{cm}^{2}$ ) 
Table 6. Distribution of the mean Log CFU/g of bacterial loads on fresh produce according to adequacy level of control measures

\begin{tabular}{|c|c|c|c|c|c|c|}
\hline \multirow[b]{2}{*}{ Microorganism } & \multirow[b]{2}{*}{ Rating $\dagger$} & \multirow[b]{2}{*}{$\mathbf{N}$} & \multirow{2}{*}{$\begin{array}{c}\begin{array}{c}\text { Prevention of cross- } \\
\text { contamination }\end{array} \\
\text { Mean } \pm \text { SD }\end{array}$} & \multirow{2}{*}{$\begin{array}{l}\text { Sanitation } \\
\text { Mean } \pm \text { SD }\end{array}$} & \multicolumn{2}{|c|}{$\begin{array}{c}\text { Protected, clean storage } \\
\text { of fresh produce }\end{array}$} \\
\hline & & & & & $\mathbf{N}$ & Mean \pm SD \\
\hline \multicolumn{7}{|l|}{ Coliforms } \\
\hline \multirow{2}{*}{ Lettuce } & Adequate & 9 & $3.84 \pm 3.09$ & $3.67 \pm 2.93$ & 11 & $3.81 \pm 2.59$ \\
\hline & Inadequate & 17 & $3.86 \pm 1.68$ & $4.20 \pm 1.98$ & 13 & $4.42 \pm 1.68$ \\
\hline \multirow{2}{*}{ Parsley } & Adequate & 10 & $3.80 \pm 2.20$ & $3.97 \pm 2.23$ & 14 & $3.95 \pm 1.94$ \\
\hline & Inadequate & 20 & $4.68 \pm 2.19$ & $5.35 \pm 2.39$ & 12 & $4.46 \pm 2.69$ \\
\hline \multirow{2}{*}{ Cucumber } & Adequate & 6 & $4.15 \pm 2.42$ & $3.92 \pm 2.48$ & 7 & $3.84 \pm 2.35$ \\
\hline & Inadequate & 9 & $3.79 \pm 1.82$ & $3.47 \pm 1.99$ & 7 & $3.61 \pm 2.06$ \\
\hline \multicolumn{7}{|l|}{$\underline{\text { E.Coli }}$} \\
\hline \multirow{2}{*}{ Lettuce } & Adequate & 9 & $1.46 \pm 2.50$ & $1.18 \pm 2.17$ & 11 & $1.19 \pm 2.31$ \\
\hline & Inadequate & 17 & $085 \pm 1.54$ & $1.23 \pm 1.77$ & 13 & $0.85 \pm 1.56$ \\
\hline \multirow{2}{*}{ Parsley } & Adequate & 10 & $0.54 \pm 0.97$ & $0.79 \pm 1.55$ & 14 & $1.15 \pm 2.05$ \\
\hline & Inadequate & 20 & $0.65 \pm 1.48$ & $0.81 \pm 1.83$ & 13 & $0.63 \pm 1.15$ \\
\hline \multirow{2}{*}{ Cucumber } & Adequate & 6 & $1.96 \pm 1.47$ & $1.79 \pm 1.47$ & 7 & $1.68 \pm 1.53$ \\
\hline & Inadequate & 9 & $1.29 \pm 1.43$ & $0.91 \pm 1.47$ & 7 & $1.36 \pm 1.53$ \\
\hline \multicolumn{7}{|l|}{ PCA } \\
\hline \multirow[b]{2}{*}{ Lettuce } & Adequate & 9 & $6.14 \pm 1.71$ & $6.10 \pm 1.54$ & 11 & $5.41 \pm 1.63$ \\
\hline & Inadequate & 17 & $5.21 \pm 1.40$ & $5.07 \pm 1.32$ & 13 & $5.41 \pm 1.63$ \\
\hline \multirow{2}{*}{ Parsley } & Adequate & 10 & $5.51 \pm 1.51$ & $5.48 \pm 1.29$ & 14 & $5.31 \pm 1.28$ \\
\hline & Inadequate & 20 & $5.49 \pm 1.21$ & $5.30 \pm 1.29$ & 13 & $5.42 \pm 1.55$ \\
\hline \multirow{2}{*}{ Cucumber } & Adequate & 6 & $5.87 \pm 1.22$ & $4.36 \pm 2.72$ & 7 & $5.84 \pm 1.11$ \\
\hline & Inadequate & 9 & $4.09 \pm 1.82$ & $4.84 \pm 1.11$ & 7 & $3.87 \pm 1.96$ \\
\hline \multicolumn{7}{|l|}{ Staphylococcus } \\
\hline \multirow{2}{*}{ Lettuce } & Adequate & 9 & $2.83 \pm 1.73$ & $3.36 \pm 2.13$ & 11 & $3.20 \pm 1.91$ \\
\hline & Inadequate & 17 & $2.67 \pm 2.43$ & $2.53 \pm 2.55$ & 13 & $2.84 \pm 2.90$ \\
\hline \multirow{2}{*}{ Parsley } & Adequate & 10 & $2.85 \pm 2.17$ & $3.16 \pm 1.87$ & 14 & $3.18 \pm 1.89$ \\
\hline & Inadequate & 20 & $2.95 \pm 1.78$ & $2.26 \pm 1.97$ & 13 & $2.13 \pm 2.08$ \\
\hline \multirow{2}{*}{ Cucumber } & Adequate & 6 & $1.80 \pm 2.02$ & $1.56 \pm 1.82$ & 7 & $1.91 \pm 1.87$ \\
\hline & Inadequate & 9 & $2.53 \pm 2.12$ & $3.24 \pm .1 .97$ & 7 & $2.86 \pm 2.12$ \\
\hline
\end{tabular}

†'Incomplete" ranking was omitted for easier presentation of data 


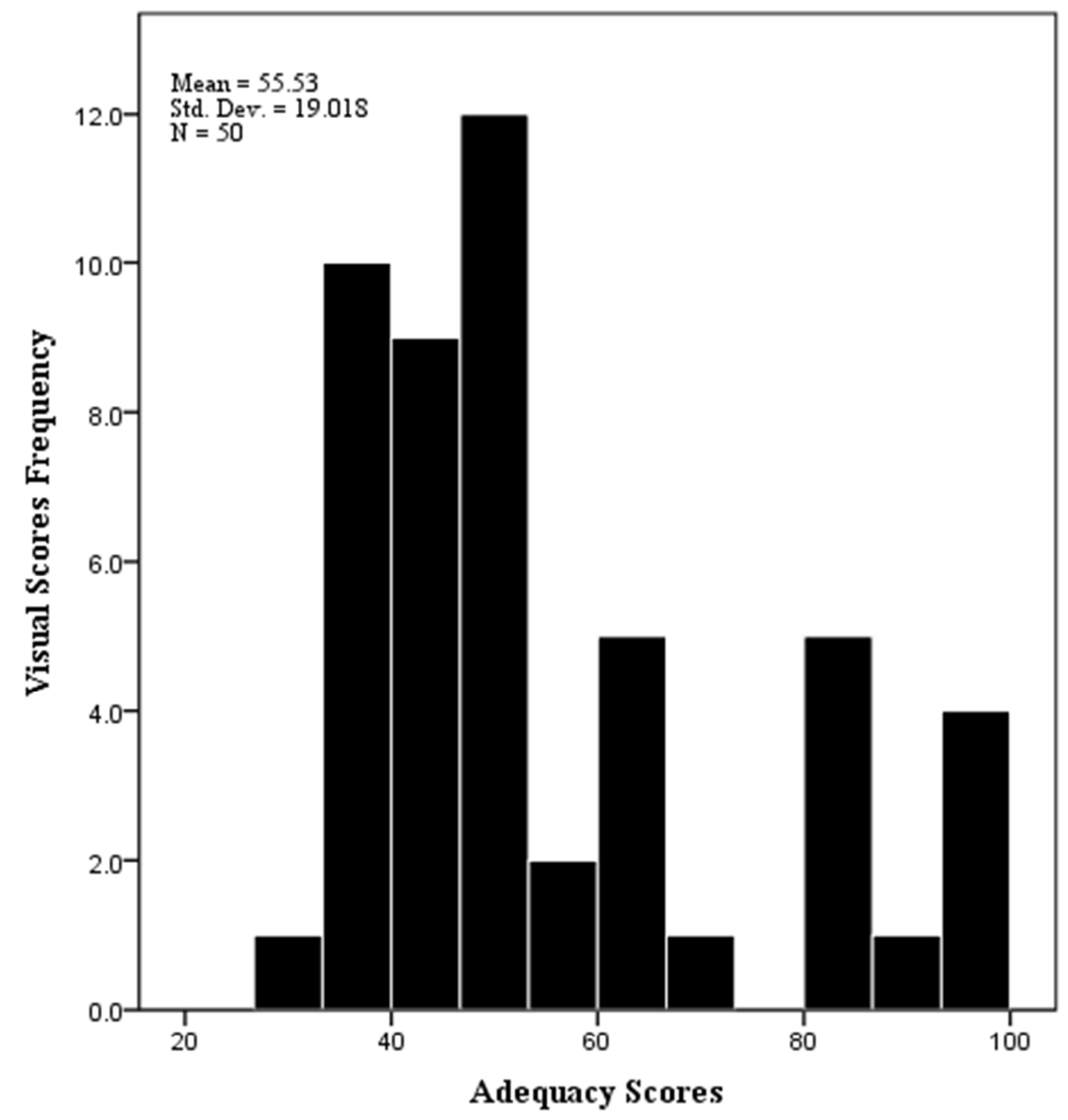

Figure 1. The distribution of total score obtained from the overall visual assessment of hygiene conditions and handling practices. 
Visual inspection component

Food handlers use gloves appropriately and correctly

Availability of handwashing sink

Sanitisers for food contact surfaces readily available

$$
\text { Zoning }
$$

Veg. prep. procedure does not promote cross contamination

Well functioning temperature monitoring gauges

Washing sink for fruits and vegetables

Structural conditions of premises

Cleanliness

$$
0 \%
$$

Inadequate

\section{$\square$ Adequate}
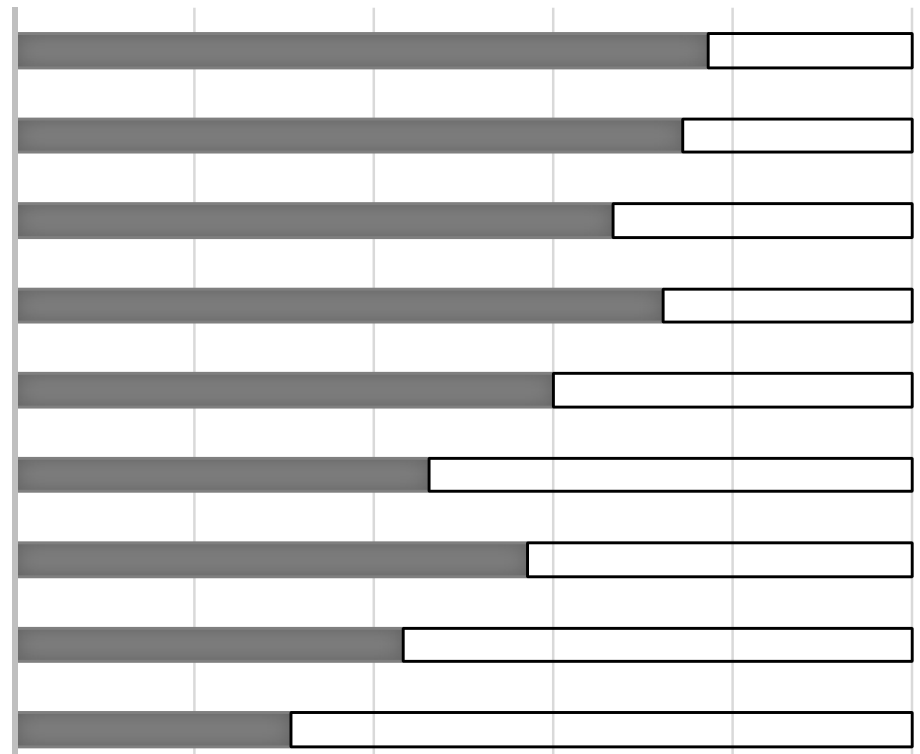

$40 \%$

$60 \%$

$80 \%$ $100 \%$

Frequency of occurence

Figure 2. Distribution of food businesses' compliance with basic hygiene requirements and control measures 


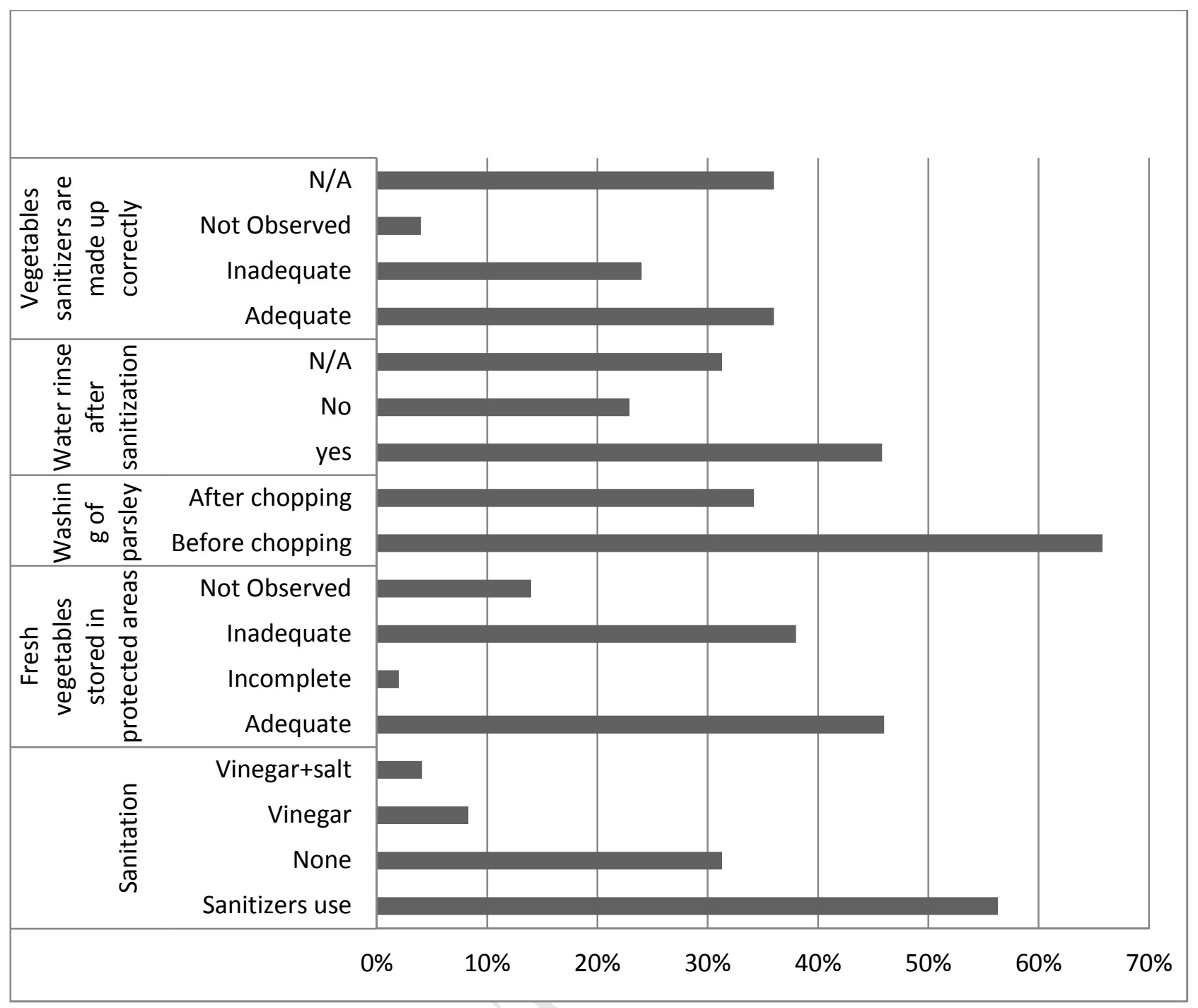

Figure 3. Distribution of food businesses' adequacy level in relation to washing and storing practices of fresh salads vegetables 

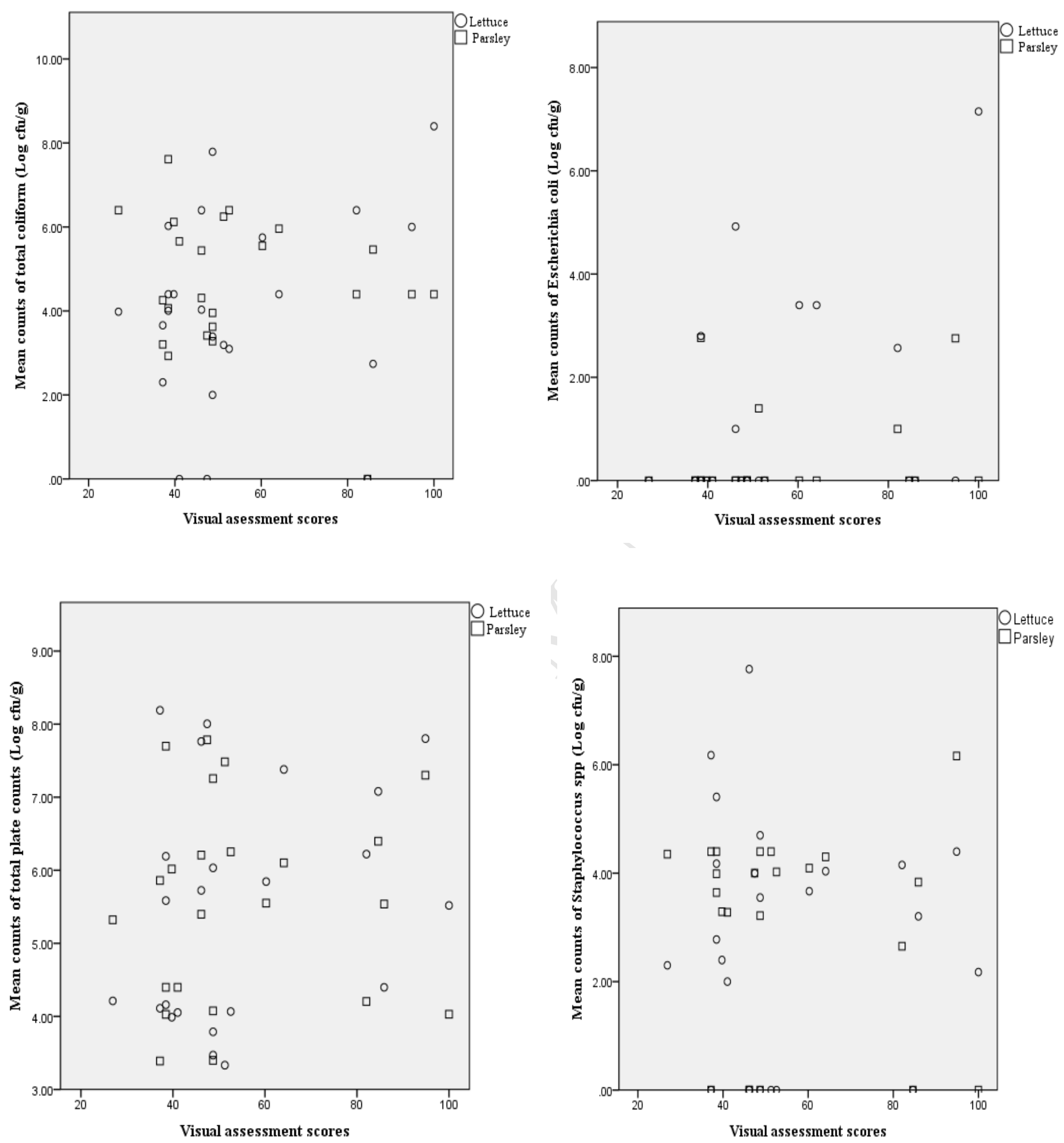

Figure 4. The distribution of microorganism levels on fresh vegetables in relation to the different values of visual assessment scores obtained on all inspected components 


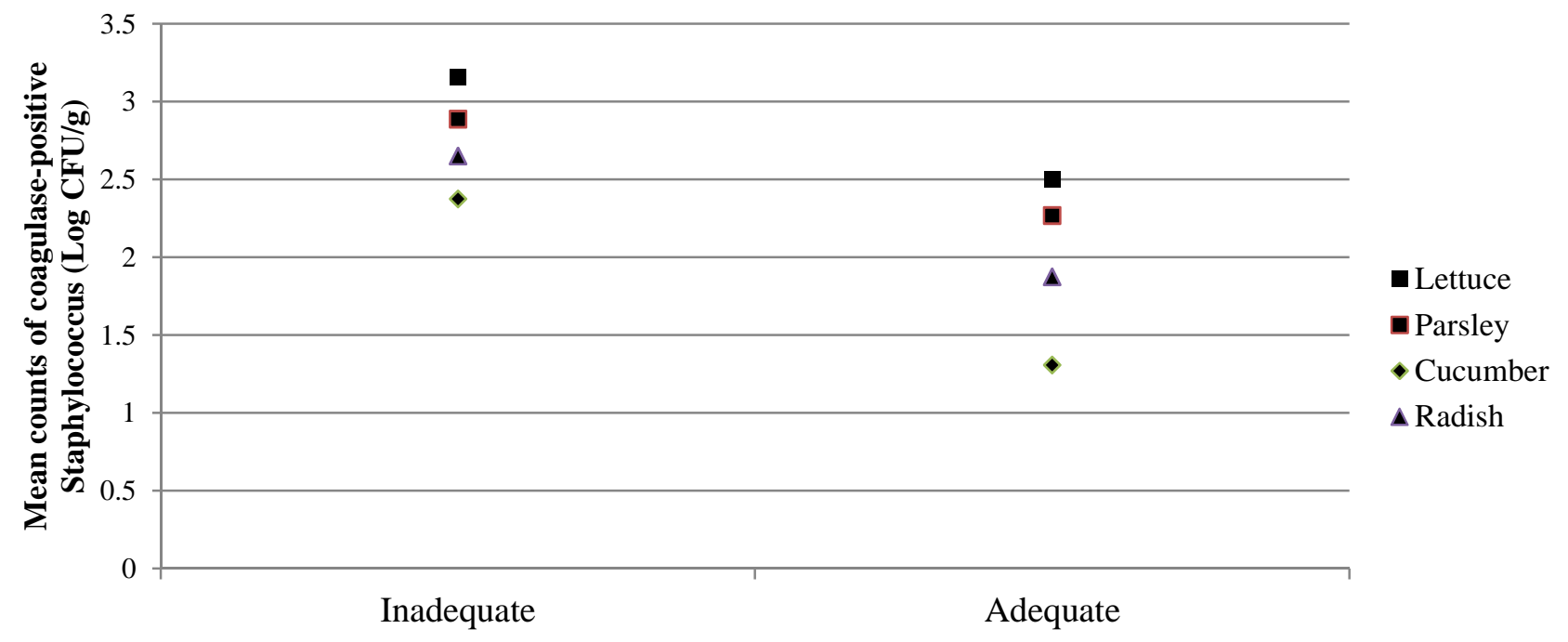

Inspection rating

Figure 5 Distribution of mean levels of Staphylococcus spp. in relation to component "Availability of handwashing facilities" 


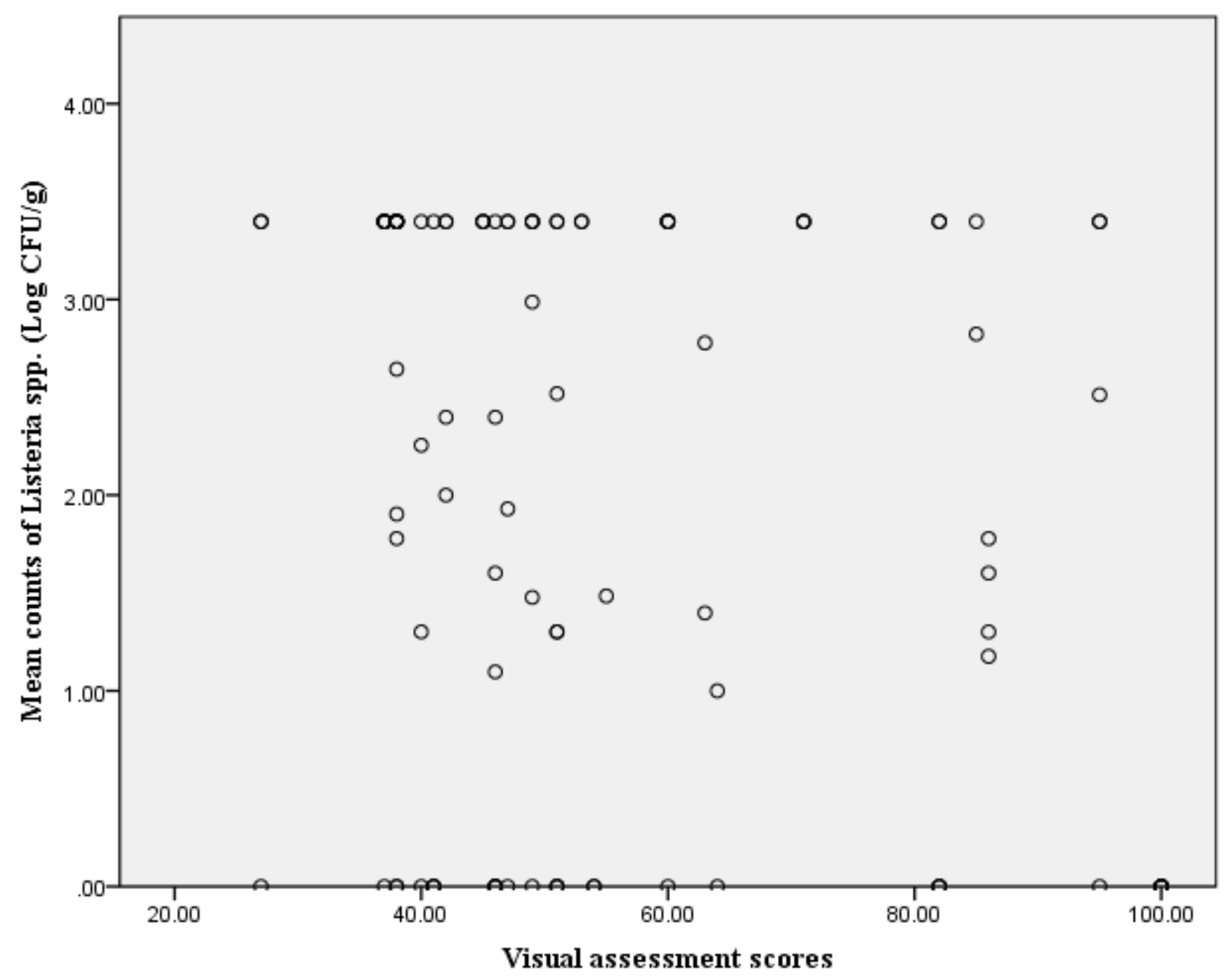

Figure 6. Distribution of Listeria spp. in relation to the visual assessment scores on all inspected components during salad vegetables preparation. 


\section{The association of microbiological quality and handling practices of ready- to-eat fresh salad vegetables with food safety environment in restaurants: Case study in Lebanon}

\section{Highlights}

1. Microbial loads on salads vegetables, hygienic conditions/practices were assessed.

2. Association of microbiological quality with visual assessment scores was tested.

3. Listeria monocytogenes and Salmonella spp. were detected.

4. There was no significant relationship with the total visual assessment scores

5. Correlation of cross-contamination components to Listeria levels was significant

6. Poor cleaning can possibly be linked to Listeria levels in salads vegetables. 